\title{
A collective navigation hypothesis for homeward migration in anadromous salmonids
}

\author{
Andrew Berdahl ${ }^{1}$, Peter A H Westley ${ }^{2, *}$, Simon A Levin ${ }^{1}$, Iain D Couzin ${ }^{1}$ E Thomas P Quinn ${ }^{2}$ \\ ${ }^{1}$ Department of Ecology and Evolutionary Biology, Princeton University, Princeton, NJ, 08544, USA; ${ }^{2}$ School of Aquatic \\ and Fishery Sciences, University of Washington, Seattle, WA, 98195, USA; *Current address: School of Fisheries and \\ Ocean Sciences, University of Alaska Fairbanks, Fairbanks, AK, 99775, USA
}

\begin{abstract}
Anadromous salmon (genera Oncorhynchus and Salmo) spend much of their lives feeding in productive northern oceans and then return home to natal sites for reproduction with remarkable accuracy. The mechanisms used for navigation by individuals during migrations are thought to include geomagnetic, celestial and olfactory cues, but rarely are social interactions between individuals considered. Mounting evidence from other taxa indicates that individuals in larger groups can better sense and respond to environmental cues, thus potentially increasing their ability to navigate. Here, we propose that salmon might similarly benefit from col lective navigation on their homeward journey. To explore this, we compiled data from multiple studies and found strong evidence that rates of successful homing increase with population abundance, consistent with collective navigation. We then discuss how collective navigation could benefit salmon during each stage of their seaward and homeward migrations, and complement this with a review of salmon sociality. Next, we analyse historic high seas catch records and provide new insight into schooling structure of salmon in the marine environment. We argue that collective navigation likely represents a presently under appreciated
\end{abstract}

\author{
Correspondence: \\ Andrew Berdahl, \\ 106A Guyot Hall, \\ Department of \\ Ecology and \\ Evolutionary Biology, \\ Princeton University, \\ Princeton, NJ, \\ 08544, USA \\ Tel.: +1 (609) 258- \\ 1491 \\ Fax: +1 (609) 258- \\ 1712 \\ E-mail: berdahl@ \\ gmail.com
}


mechanism enhancing the navigational ability of salmon as well as other migra tory species, and outline critical tests of our hypothesis.

Keywords Collective behaviour, density dependent dispersal, homing and straying, meta population dynamics, orientation, schooling

\section{Introduction}

The annual return of anadromous (i.e. sea going) Atlantic and Pacific salmon (genera Oncorhynchus and Salmo, family Salmonidae, hereafter 'salmon') to freshwater for reproduction has captured the imagination of scientists, naturalists and native people alike for centuries (NRC 1996). An integral aspect of salmon biology is their remarkable ability to navigate back to natal locations for reproduc tion after foraging at sea (Oncorhynchus reviewed by Quinn 1993; Keefer and Caudill 2013; Salmo: Jonsson and Jonsson 2011). Homing (philopatry) and straying (dispersal) are fundamental to sal mon ecology, shaping the evolution, and guiding the management of populations (Quinn 2005). The frequency of homing versus straying is thought to exist in a dynamic balance, shaped by site specific selection pressures on the spawning and rearing grounds (Quinn 1984, 1993; Hendry et al. 2004).

The proximate mechanisms that facilitate the imprinting and homing processes are increasingly well known [recently reviewed by Ueda (2012) and Keefer and Caudill (2013)]. Briefly, sequential imprinting by downstream migrating juveniles to unique odours of local environments appears to provide a road map during the freshwater phase of the return migration by adults (Scholz et al. 1976; Hasler and Scholz 1983; Dittman and Quinn 1996). As freshwater cues are too diluted to be detected at sea, salmons appear to rely on geo magnetic gradients to guide them back to the estuaries of their local rivers (Putman et al. 2013), where olfactory cues then predominate (Scholz et al. 1976).

Collective behaviour has been shown, both theo retically and experimentally, to increase the ability of individuals in groups to sense and respond to their environments for many taxa, including fishes (Couzin 2009; Berdahl et al. 2013). However, at all phases of the life cycle of salmon, migratory orientation has been examined as an individual level process. Although schooling and other forms of aggregative behaviour are known in salmon, to date a role of collective behaviour in orientation and navigation has not been formally articulated (but see Larkin and Walton (1969) for an early appreciation of the possible role of interindividual interactions).

We present a synthesis of existing datasets, novel analysis, and pertinent empirical and theo retical literature to explore the potential for collec tive navigation to operate during the adult salmon homing migration. To explore this hypothesis, we first compile published data on homing and stray ing as functions of abundance and find a signifi cant and consistent trend of declining straying with abundance, in multiple populations and spe cies. Next, we review the literature on collective behaviour and describe how various aspects could improve the navigational ability of salmon at each stage of their homeward breeding migrations by following a hypothetical cohort of migrating sal mon from the ocean to their spawning locations. Finally, we analyse data from high seas salmon research and review relevant literature suggesting that salmon migrate in groups or at least at densi ties high enough to use social information, and they are able to effectively sort into destination specific groups.

\section{Homing and abundance}

Quinn and Fresh (1984) reported evidence that straying decreased with increasing numbers of returning adults and noted that it was consistent with the findings of Sholes and Hallock (1979). Later, in a review of salmon homing and straying, Hendry et al. (2004) found that this trend was indeed widespread, stating that while the mecha nism was unclear, the phenomenon presents an 'interesting avenue for future theoretical work' [p. 72]. We hypothesize that navigational ability is enhanced in migrating salmon by acting collec tively, providing an explanation for the empirical relationship between abundance and rates of hom ing or straying by adults. 
To explore this idea, we identified seven inde pendent studies reporting both abundance and straying rate (Table 1), estimated by tag recovery programs (e.g. see Regional Mark Processing Cen ter at www.rmpc.org) that quantified the number of fish returning to natal and non natal streams. Figure 1 shows the negative trends between stray ing rate and run size in all seven studies. In this fig ure, we divided the data from Jonsson et al. (2003) into separate panels for wild and hatchery fish to examine the difference in the trend between these groups, but to be conservative, consider the study of a single independent sample. It is very unlikely that seven negative slopes of seven datasets arose by chance alone (binomial test, $P$ 0.008). Several of the studies included data from multiple populations, and negative trends were observed in $74 \%$ of the populations, which again was unlikely to have occurred from chance (binomial test, 25 negative trends of 34 trends, $P<0.01$ ). Thus, at the regional (study) and local (population) scale, this consistent trend of decreased straying with increasing abundance was found in Chinook salmon (Oncorhynchus tshawytscha), coho salmon (Oncorhynchus kisutch), steelhead trout (Oncorhynchus mykiss), and Atlantic salmon (Salmo salar) across various locations and populations (Table 1).

The remarkably swift colonization of large sec tions of new habitat following point introduction of salmon provides additional, albeit indirect, evi dence of a negative relationship between straying and abundance. Non native Chinook salmon introduced into a single river in New Zealand spread in just a few generations to essentially all the rivers where they were ever found (Ayson 1921). This rapid expansion would not be expected based on contemporary straying rates in those populations (Unwin and Quinn 1993).
Therefore, it appears that straying rates must have been much higher in these initial, sparse, populations. Similar flash expansions due to high straying have been documented in populations introduced at low density in Patagonia (Becker et al. 2007; Correa and Gross 2008) and the Great Lakes (Emery 1981; Kwain and Lawrie 1981).

\section{Collective behaviour}

Collective behaviour (schooling, flocking, herding, etc.) is ubiquitous among animal taxa (Krause and Ruxton 2002) and is particularly common in fishes (Pitcher and Parrish 1993). A significant benefit for many organisms that live in groups may be collective intelligence (Couzin 2007, 2009), and mounting evidence demonstrates that simple interactions among individuals with rela tive unsophisticated behaviour may produce com plex outcomes that are adaptive at the group level (Bonabeau et al. 1999b; Seeley and Buhrman 1999; Franks et al. 2002; Camazine 2003; Sump ter 2006; Berdahl et al. 2013).

Here, we are interested in a particular facet of collective intelligence: navigational ability. Theo retical work predicts that collective migratory strategies might evolve under a wide range of eco logical scenarios (Torney et al. 2009, 2010; Guttal and Couzin 2010; Shaw and Couzin 2013), and it may be no coincidence that migrations and other navigational feats are often undertaken by large groups (Beauchamp 2011; Milner Gulland et al. 2011). Homing pigeons return more efficiently when released as groups than they do as individu als (Biro et al. 2006; Dell'Ariccia et al. 2008), and birds with less information can benefit from fol lowing others (Flack et al. 2012). Theories, like

Table 1 Datasets reporting straying rate as a function of run size.

\begin{tabular}{|c|c|c|c|}
\hline Study & Species & Number of populations & Location \\
\hline Sholes and Hallock (1979) & Chinook & 1 & Feather River, California \\
\hline Quinn and Fresh (1984) & Chinook & 1 & Cowlitz River, Washington \\
\hline Labelle (1992) & Coho & 6 & Vancouver Island, Canada \\
\hline Hard and Heard (1999) & Chinook & 1 & Sashin Creek, Alaska \\
\hline Schroeder et al. (2001) & Steelhead & 3 & Oregon, USA \\
\hline Jonsson et al. (2003) & Atlantic & 2 & River Imsa, Norway \\
\hline $\begin{array}{l}\text { P.A.H. Westley, T.P Quinn and } \\
\text { A. Dittman (Unpublished data) }\end{array}$ & Chinook & 20 & Columbia Basin, USA \\
\hline
\end{tabular}



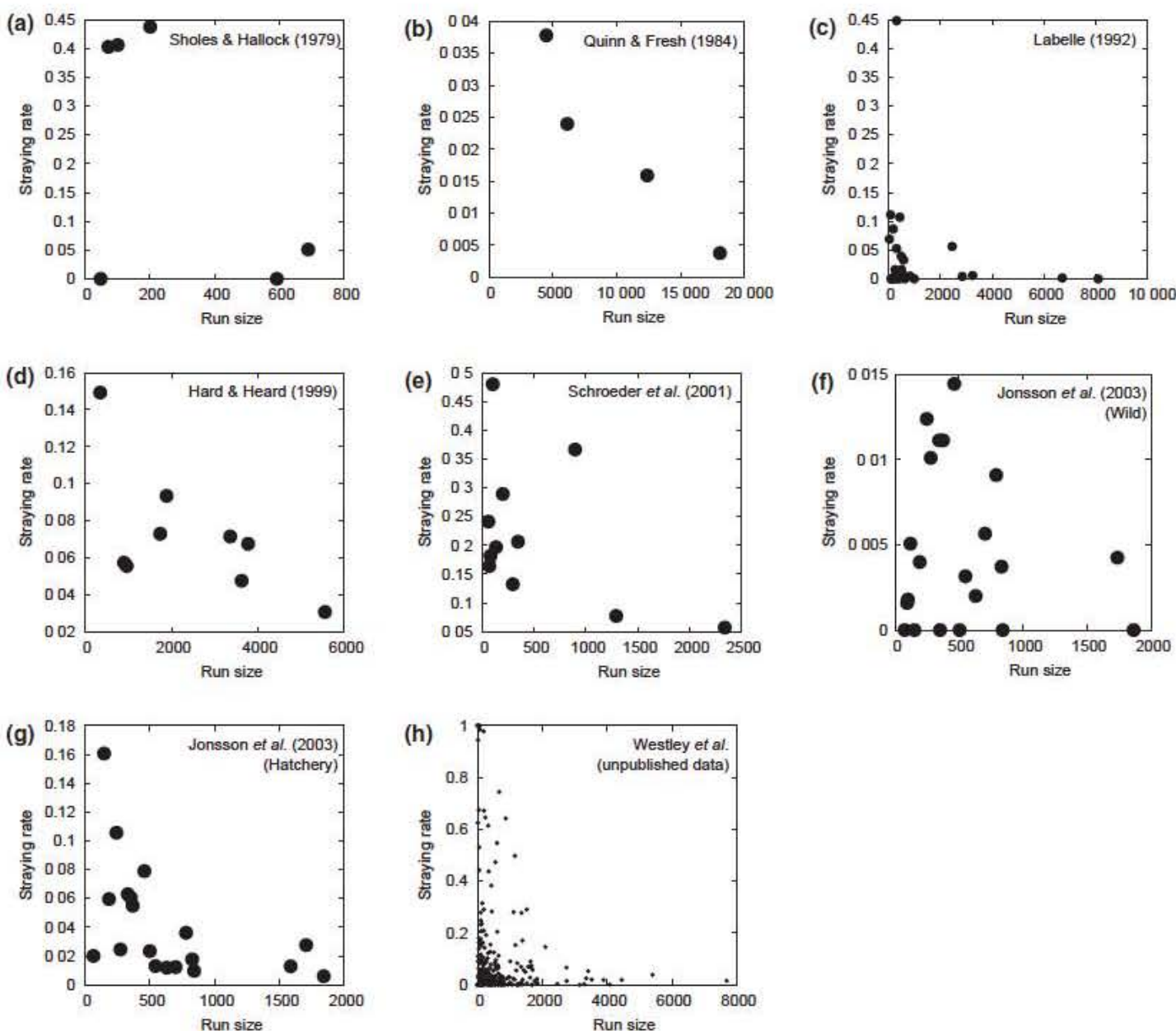

Figure 1 Straying rate as a function of run size. We plot the proportion of salmon straying from their natal river as a function of the total number of salmon from that population returning that year for every study reporting such data. In all the sets, representing four species, there is a negative relationship between the two variables, indicating salmons stray less in years of greater abundance. Naturally, each population has a different range of run sizes and straying rates mediated by the particular environmental conditions that population faces; thus, we do not expect the same quantitative trend in each panel. Note we have partitioned the data of Jonsson et al. (2003) into separate panels showing data for wild and hatchery fish.

the 'many wrongs principle' (Larkin and Walton 1969: Grünbaum 1998; Simons 2004; Codling et al. 2007). predict that such groups may aver age out errors made by individuals, thereby enhancing the individual navigational strategy (see Box 1). Using an evolutionary model of migrant populations Guttal and Couzin (2010) showed that when interactions among organisms are relatively inconspicuous, such as when migrants do not form coherent groups, they may nevertheless provide vital social cues that aid migration. It has also been shown theoretically
(Torney et al. 2009, 2011) and empirically (Berdahl et al. 2013) that a group's ability to climb a gradient can emerge from social rules alone, without any individual level ability to esti mate the gradient. In this case, the group does not enhance the individual strategy because no individual taxis exists; navigation would be entirely absent for a lone traveller, but nonethe less emerges at the group level. In general, collec tive behaviour could simultaneously do both: that is, it can enhance individual strategies as well as lead de novo to group level emergent effects. 


\section{Box 1. Collective directional estimates}

In 1907, Sir Francis Galton was able to estimate the dressed weight of an ox to within a pound by pooling guesses made by many independent observers (Galton 1907). Today, we know this effect as the 'wisdom of the crowd' (Surowiecki 2004) or the 'many wrongs principle' (Simons 2004) averag ing over many independent estimates tends to suppress outliers. It is thought that this principle applies to animals during their migrations when they are faced with difficult orientation tasks (Larkin and Walton 1969; Simons 2004; Codling et al. 2007). Although they may all be intent on the same target, each individual might have some error in its estimation of in which direction that target lies. These errors may be due to noise in whatever cue they are using to orient themselves, noise in their sensing of that cue, or cognitive limitations in processing directional information from the cue. Group move ment, such as schooling or flocking, acts to pool the many individual orientation preferences of the group into an average heading, suppressing noise about the mean.

Here, we consider a group of salmon. Each one, using geomagnetic cues, estimates the heading needed to make landfall near the estuary of its natal river system. We define accuracy as the probability of ori enting towards a small target of angular size $\phi$ (for convenience, and without loss of generality, we will say that $\phi$ is located due north, at $\theta \quad 0)$. As in Larkin and Walton (1969), we assume that the esti mates of each individual can be approximated by a circular normal distribution, all centred about the correct direction, $\theta \quad 0$, that is, there is no bias. Accuracy for a single individual is then given by

$$
A(\sigma)=\int_{-\phi / 2}^{\phi / 2} C(\theta, \sigma) d \theta
$$

where $C(\theta, \sigma)$ is the circular normal distribution (probability to orient at angle $\theta$ ) with variance $\sigma$. Due to the sources of noise discussed above, the variance in this distribution might be quite high, so accu racy, $A$, will be low. If the group orients itself by effectively averaging the heading estimate of each fish, as a consequence of the law of large numbers, the variance in the distribution of group orienta tions declines as $1 / \sqrt{ } N$, where $N$ is the number of members in the group (see Larkin and Walton (1969) for details). Thus, for larger group sizes, accuracy is increased nonlinearly.

In Fig. 2, we plot the individual accuracy required to achieve a specific group accuracy for such an orientation task. For a specific group accuracy, the onus on each individual fish to make an accurate directional estimate monotonically decreases as group size increases. Alternatively, by tracing a hori zontal line across the plot, one can see that for a set individual accuracy, increasing group size dramat ically increases the group accuracy. This demonstrates a simple mechanism by which salmon could use collective behaviour to achieve navigation not possible by an individual, or use collective behav iour to attain the same level of accuracy during migration, but with a reduced cost to each individual.

\section{Collective navigation and salmon migration}

Here, we explore the potential role of collective navigation to aid migration of an archetypical cohort of salmon crossing the high seas from their feeding areas to coastal waters, locating the estu ary of their home river, and ascending a network of tributaries to their natal site.

\section{Migration from the high seas}

Tagging studies indicate that once salmons begin their migration home, they swim at roughly the most energetically efficient speed (ca. 1 body length per second or ca. $2 \mathrm{~km} \mathrm{~h}^{-1}$ ) and exhibit highly oriented travel because they routinely tra vel $3050 \mathrm{~km} \mathrm{day}{ }^{-1}$ directly towards their home stream (reviewed by Quinn 2005). A growing body of work reveals that the salmon can detect and use Earth's magnetic field as a compass (Quinn 1980; Quinn and Brannon 1982) or a map (Bracis and Anderson 2012; Putman et al. 2014). Gradients of salinity and temperature are also available to the salmon during this phase, and they may use them to find productive foraging conditions (Leggett 1977), but it is unlikely that they use those cues during their homeward migra tion (reviewed in Quinn 2005). 
Assuming that each fish has some inherent ori entation capacity based on geomagnetic or other cues, individuals ostensibly can use schooling to pool their estimates and cancel out the errors and noise in individual directional estimations. This collective pooling of individual abilities into the school would enhance individual level orientation capacity (Larkin and Walton 1969; Grünbaum 1998). Moreover, the group can effectively be led by only a few informed individuals (Couzin et al. 2005; Guttal and Couzin 2010; Mueller et al. 2013); as group size increases, the fraction required to lead it successfully diminishes (Couzin et al. 2005; Guttal and Couzin 2010).

In Box 1, we present a toy model for collective orientation, relevant to salmon making their way from their feeding grounds on the high seas to the mouth of their natal stream, and the results are shown in Fig. 2. The key result is that the naviga tional onus on the individual decreases as group size increases and that high rates of group accu racy can result through the co migration of rela tively poorly orientating individuals. Simulations indicate that directional orientation is needed for salmon to accomplish these migrations, but such models have typically treated salmon as individu

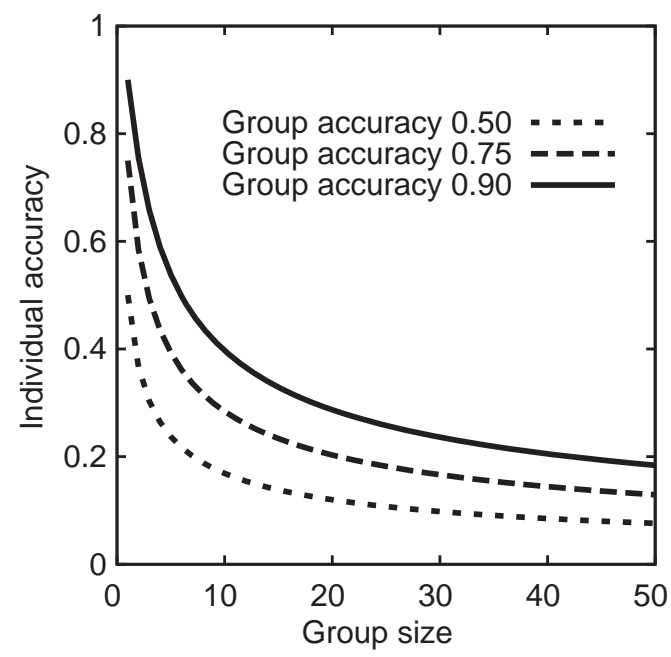

Figure 2 Individual accuracy required to achieve a specific group accuracy for a directional estimation task. Here, accuracy is defined as the probability the directional estimate is within a small, fixed and angular area around the correct direction (see Box 1 for details). For a certain group accuracy, the onus on each individual fish to make an accurate directional estimate monotonically decreases as group size increases. For a given individual accuracy, the group accuracy increases monotonically with increasing group size. als, deriving no benefit from group interactions (e.g. Pascual and Quinn 1991; Dat et al. 1995; Bracis and Anderson 2012).

\section{Locating and entering the estuary}

As salmon approach land, their environment changes dramatically. Variations in salinity and water temperature increase, and the water becomes vertically stratified closer to shore. Cur rents increase and reverse due to tidal action and interactions with the continental bathymetry. Once in coastal waters, the sea floor comes into sensory range of the migrating fish and they encounter intricate shorelines. Compared to the simplicity of the open ocean, the array of islands, bays, straits and narrows is a veritable maze. Although the precise timing of when geomagnetic or celestial cues give way to olfactory processes is unknown, presumably there is a shift towards the latter during the transition through the estuary (e.g. Hasler 1966).

Experimental evidence reveals that fish in larger groups are better able to sense and respond to complex gradients, like those salmon encounters in estuaries (Lenwood et al. 1982; McNicol et al. 1996; Berdahl et al. 2013). As outlined in Box 1, schooling may allow migrating salmon to pool noisy individual estimates of the appropriate direc tion to travel (Larkin and Walton 1969; Grünbaum 1998; Codling et al. 2007) also see Fig. 2. In addition, larger groups, by virtue of spanning a larger area, might act like a sensory array, sampling for the 'signal' at a spatial scale larger than the 'noise' (Couzin 2007). Further more, in gradient tracking and source detection tasks, grouping can lead to a directional response even when no single individual can measure the gradient, and the strength of this response increases for larger groups (Torney et al. 2009, 2011; Berdahl et al. 2013).

\section{Negotiating the river network}

Once migrating salmon enter their natal river sys tem, a positive rheotactic response (i.e. upstream swimming) triggered by detection of an imprinted odour is sufficient to navigate upstream (Johnsen 1982). Fish might search for the most efficient route upstream to minimize energy costs (Hughes 2004; McElroy et al. 2012), but for long stretches, navigation is relatively simple upstream. 
However, the salmon face a binary decision at each river confluence concerning which branch to ascend.

Locating a small tributary that enters much lar ger streams may be difficult for migrating salmon. In this case, collective gradient tracking strategies perpendicular to the flow, combined with the rheo tactic response upstream (Torney et al. 2009), would facilitate salmon being on the correct side of the channel in a good position to find these small tributaries. At confluences of similar sized tributaries, salmon presumably could sample the odour cues of both branches by travelling a short distance up both or by simply traversing the river channel at the confluence perpendicular to the direction of flow. Indeed, short term sampling of non natal streams appears to be common in sal mon migrating in large rivers (Keefer et al. 2009).

The two river branches might have very similar chemical composition, and distinguishing between them could be difficult (Dittman and Quinn 1996). Larger groups of fish are better able to sense odour cues (Lenwood et al. 1982; McNicol et al. 1996). Furthermore, empirical (Sumpter et al. 2008; Ward et al. 2008, 2011; Arganda et al. 2012) and theoretical (Condorcet 1785; Ladha 1992; King and Cowlishaw 2007) work on voting and binary decision making shows that larger groups are often able to choose the superior option more often when given two choices. However, this increase in accuracy may be non monotonic and thus maximized at finite group sizes (Kao and Cou zin 2014). In Box 2, we present a generic simple model for collective binary decisions based on Con dorcet's (1785) jury theorem, analogous to the binary decisions faced by migrating salmon when they confront tributaries. Figure 3 illustrates the shape of the relationship between group accuracy and individual accuracy for groups of varying size. As group size increases, the trend becomes increasingly nonlinear. Thus, for a fixed individual accuracy, the probability the correct branch is chosen increases monotonically with group size.

\section{Box 2. Collective binary decisions}

Much empirical work on binary decision making by animal groups shows that larger groups are often able to choose more accurately the superior option (Sumpter et al. 2008; Ward et al. 2008, 2011; Ar ganda et al. 2012). Condorcet's (1785) jury theorem is a simplistic model to give us intuition as to why this might occur (see King and Cowlishaw (2007) for a review). In this model, each individual votes for one of the two options and the group, as a whole, adopts the opinion of the majority. Con sider a group of salmon heading upstream; paused at a river confluence, each individual salmon in the group estimates which of the two rivers leads to its natal site and chooses the correct branch with probability $P$, where $P>0.5$. If the group, through schooling dynamics, moves in the direction of the majority, they will chose the correct branch with probability $Q$, given by a cumulative binomial distri bution:

$$
Q(p, N)=\left[\sum_{k>N / 2}^{N}\left(\begin{array}{c}
N \\
k
\end{array}\right) p^{k}\left(\begin{array}{ll}
1 & p)^{N-k}
\end{array}\right]+\frac{1}{2}\left(\begin{array}{c}
N \\
N / 2
\end{array}\right) p^{N / 2}(1 \quad p)^{N / 2}\right.
$$

(Note that the second term is absent when $N$ is an odd number.) We illustrate this highly nonlinear response in Fig. 3, where we plot group accuracy, $Q$, against individual accuracy, $P$, for various group sizes. The larger the group, the more nonlinear the group response are and the more likely the correct branch is chosen. In this simple model, for large group sizes, $Q$ approaches 1 (they vote deterministi cally for the correct branch) even when $P$ is very close to 0.5 ; that is, individually, the fish can barely do better than random guessing.

\section{Salmon schooling}

For salmon to benefit from collective navigation, they must travel in groups, or at least at densities sufficient for them to exchange information [such densities need not, however, be particularly high (Guttal and Couzin 2010)]. For most fish species, sight, odour and the lateral line sense are the 


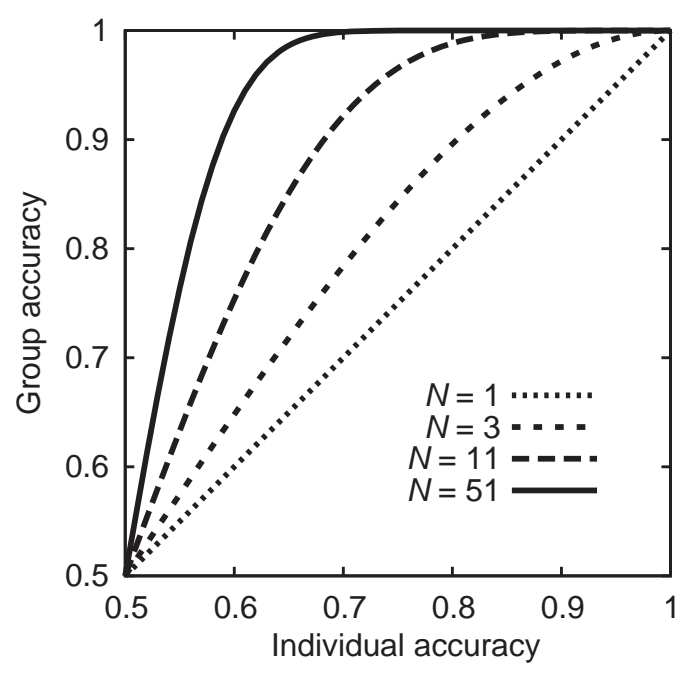

Figure 3 Group accuracy as a function of individual accuracy for various group sizes. In this simple toy model, each individual votes for one of the two options in a binary decision making task and the group collectively chooses the opinion of the majority (see Box 2 for details). Salmons face such binary decisions at river confluences on the river phase of their migration. Fish have been shown to 'vote' through schooling dynamics without any explicit signalling (Sumpter et al. 2008; Ward et al. 2008).

primary sources of social information (Partridge and Pitcher 1980; Faucher et al. 2010; Strand burg Peshkin et al. 2013). Salmon can detect pop ulation specific odours (Courtenay et al. 1997) so salmon might be able to travel beyond visual range but nevertheless maintain contact by follow ing pheromone gradients (Couzin and Franks 2003; Detrain and Deneubourg 2006). Such pher omones secreted by adults at a more advanced stage might provide additional cues to guide subse quent migrants. This could be interpreted as a sort of collective intelligence at the population level, but at the individual level due to the signal being asymmetric, it would bestow greater benefit on later migrating individuals.

Salmon likely experiences selective pressure to group for a variety of reasons, including protection from predation (Handegard et al. 2012; Marras et al. 2012) from larger fish, birds, marine mam mals, and sharks, for group hunting (Handegard et al. 2012), hydrodynamic benefits (Ross et al. 1992; Herskin and Steffensen 1998; Portugal et al. 2014), and tracking gradients associated with appropriate living conditions or patchily distrib uted prey (Couzin 2007; Torney et al. 2009, 2011; Berdahl et al. 2013). Such coordinated group living may confer benefits of collective navi gation during migrations, even if the grouping originally evolved for other reasons.

\section{Schooling as juveniles}

Prior to migrating to sea as juveniles, some species of salmon tend to school (e.g. sockeye salmon (Oncorhynchus nerka) in lakes), whereas others tend to be territorial as they feed in streams where food is limited and habitat is defensible (e.g. Atlantic sal mon and coho salmon: Quinn 2005; Jonsson and Jonsson 2011). A decrease in territorial behaviour and increase in schooling tendency characterize the transition from a life in freshwater to the marine environment (reviewed by Hoar 1951; Fol mar and Dickhoff 1980). Despite clear differences in the patterns and degree of schooling among species (Hoar 1976), there is compelling evidence that juvenile salmons migrate in schools to the sea and that in some species schooling increases their orientation and speed (Hoar 1958a). Extensive observations of sockeye salmon smolts migrating through Babine Lake to the Babine River and downstream to the ocean revealed hundreds of dis crete schools of sockeye salmon smolts (Groot 1965, 1972). Babine Lake is about $160 \mathrm{~km}$ long and intricate, so well oriented migration is needed to locate the outlet (Johnson and Groot 1963). Indeed, simulations indicated that considerable ori entation by fry and smolts was needed to match observed shifts in distribution. However, as with simulations of migration at sea, the potential role of social interactions was not considered (Simms and Larkin 1977).

\section{Schooling in marine waters}

Observing fish behaviour in the open ocean is diffi cult, and accordingly, the social tendencies of sal mon are not well understood during the marine stage of their life cycle. To explore the degree to which salmon may be schooling on the high seas, we analysed the catch records (number of salmon of each species caught) in an experimental high seas purse seine fishery in the northern Pacific Ocean from 1956 to 1991 (data provided by K. W. Myers, High Seas Salmon Research Program, School of Aquatic and Fishery Sciences, University of Washington, Seattle, Washington). To the extent possible, sampling methods were standardized over years and boats (Hartt 1975). After we removed 
records that had anomalies (e.g. the net twisted dur ing the set), the dataset comprised 3520 purse seine hauls, made opportunistically without sonar or fish finding gear to guide the operations.

Figure 4 shows the probability distribution func tion (PDF) catch size for each species, from the perspective of both the fishers (Fig. 4a) and the fish (Fig. 4b). If salmon were distributed randomly and independent of each other, we might expect catch sizes to follow a Poisson distribution with mean equal to their mean density multiplied by the volume of water the purse seine net strains. However, with the possible exception of steelhead (by far the least numerous species), the observed distributions of catch sizes are not consistent with a Poisson distribution. Instead, the distributions tend to be very broad, spanning several orders of magnitude. The most common catch size was zero ( $41 \%$ of the catches). The rarity of finding any fish, combined with the possibility of finding many when one finds any, suggests that the fish were aggregated in time and space. The three species showing strongest aggregation tendency (pink (Oncorhynchus gorbuscha), chum (Oncorhynchus keta) and sockeye) are the most numerous species and also those with the strongest schooling tendencies and least aggressive behaviour as juveniles (Hoar 1958b; Hutchinson and Iwata 1997).

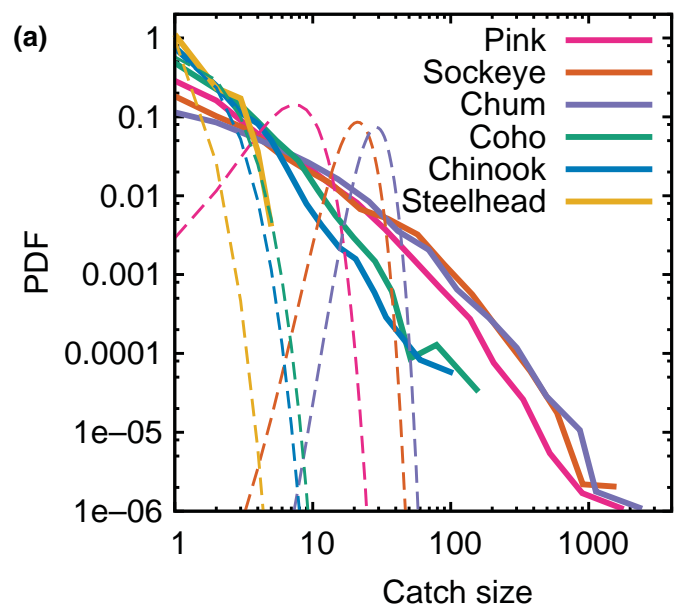

In Fig. 4, catch size is a direct measure of local density of fish, where the spatial scale is a function of the area sampled by the purse seine net. We use catch size as a proxy for group size, but note that this may under sample larger groups if they exceed the size of the net (Makris et al. 2006) or if larger groups more easily evade capture. With this in mind, we note that the catch size distribution we observed for salmon is consistent with the broad distributions of group sizes predicted for (Gueron and Levin 1995; Gueron 1998; Niwa 2004; Ma et al. 2011), and observed in, fission fusion populations, including those of fish (Bona beau et al. 1999a; Makris et al. 2006).

As the purse seine data included multiple age classes of fish (i.e. not only those actively migrat ing home), clustered catches may have arisen if fish were concentrated in areas conducive to feed ing. Regardless of their motivation, our analysis shows that fish are patchily distributed on the high seas at densities that would permit the exchange of social information, even if they are not in highly polarized schools (although it does not preclude such schools). Furthermore, the schooling tendency may increase as fish begin their homeward migration. Consistent with this, data from Cooke et al. (1987) show that salmon density increases greatly and significantly

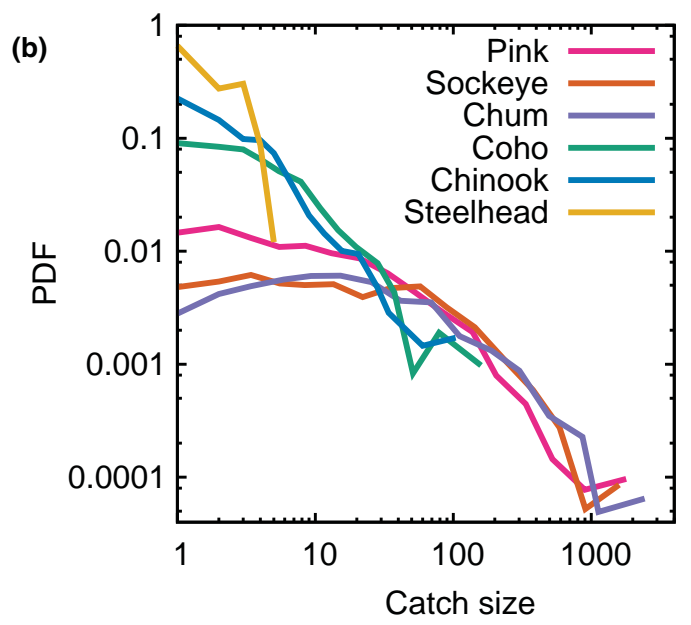

Figure 4 Catch size distributions. (a) The probability distribution function (PDF) of nonzero haul sizes, measured in number of non juvenile salmon, for the experimental purse seine fishery (data provided by K. W. Myers, High Seas Salmon Research Program, School of Aquatic and Fishery Sciences, University of Washington, Seattle, Washington). Each colour represents data for a single species. The thinner dashed lines show the corresponding Poisson distributions, assuming the salmons are distributed randomly with the same mean density. The actual distributions (thick solid lines) are broad and non Poissonian, indicating that the fish are aggregated. (b) The PDF of the likelihood of a fish being in a catch of a particular size from the same dataset. 
(P 0.00047; Wilcoxon signed rank test), as they near shore the (min:median:max) purse seine haul was (0:2:36) offshore and (0:20:2500) onshore. While this may reflect a response to geo metric constraints or an increase in their catch ability near shore, it could also indicate an increased sociality in preparation for the mounting difficult navigational tasks ahead.

We note that Mishima et al. (1965) documented evidence of salmon grouping at sea based on catches in gillnets. Using acoustic surveys, Nero and Huster (1996) found many small schools (2 4 individuals) of salmon (species unknown) spaced uniformly at small scales $(2200 \mathrm{~m})$ and aggre gated at larger scales (400 $2000 \mathrm{~m})$. The uni form, rather than random, spacing suggests frequent interactions between the small groups. Thus, the large scale aggregation may exist as a meta group, which would be large enough to span environmental gradients relevant for naviga tion. Due to the nature of the salmon density dis tributions (Fig. 4) and their relatively sparse sampling scheme, Nero and Huster (1996) likely missed the very large aggregations in the tail of the distribution, which are numerically rare, yet common from the point of view of an individual, by virtue of those larger groups containing a proportionally larger fraction of the population (see Fig. 4b).

\section{Schooling during upstream migration}

On the freshwater stage of their adult spawning migration, salmons often travel together (Banks 1969 and references therein). Schooling behaviour has long been noted by managers tasked with counting the numbers of returning salmon to freshwaters. Writing about the patterns of upstream migration by adult sockeye salmon to the Wood River, Alaska, Mathisen (1962) noted, 'On days of heavy escapement [large numbers of returning fish] they can be observed moving in continuous bands close to both river banks. On days with small escapements the salmon travel in schools of a few to perhaps 100 fish and usually ascend along only one river bank.' [p. 355]. Simi larly, pink salmon in southeast Alaska tends to move into freshwater as coherent schools (David son et al. 1943). Moreover, movement of salmon into streams for spawning can occur in strong 'pulses' of fish entering at once, even in the absence of obvious environmental stimuli to catalyse the pulses, like increases in flow (e.g. Lorz and Northcote 1965). These group behaviours may be related to predator avoidance, energy con servation through drafting (Hughes 2004) or other effects, but they are also consistent with orienta tion and consensus decision making, and the vari ous factors are not mutually exclusive.

\section{Stock-specific sorting}

Multiple populations of salmon overlap in time and space while at sea; for example, populations of sockeye salmon from throughout their North American distribution were caught and tagged from a single net sample in the Gulf of Alaska (Ne ave 1964). Thus, if salmons are to form schools for their homeward migration, they must sort into stock or population specific groups. This could be an iterative process, with the necessary homogene ity increasing as the migration progresses. Below, we suggest three ways the salmon might achieve this sorting.

First, substantial evidence indicates that salmon can detect the unique pheromones of their local population and related individuals, and often choose to associate accordingly (Quinn and $\mathrm{Bu}$ sack 1985; Quinn and Hara 1986; Winberg and Olsén 1992; Courtenay et al. 1997; Olsén et al. 2004; Fraser et al. 2005). Thus, while the phero mone hypothesis proposed originally by Nordeng (1971, 1977) for homing has fallen out of favour as a holistic framework based on a lack of evi dence (e.g. Brannon and Quinn 1990), the detec tion of population specific pheromones may lead to correct group sorting (Ward et al. 2007; Griffiths and Ward 2011; and references therein) and would thus be important to the collective navigational process. Moreover, genetic evidence indicates that Pacific salmon populations sponta neously sort by stock in space and time as they near shore (Dann et al. 2013). Second, popula tions within watersheds often differ in the timing of their return to freshwater, which largely reflects differences in thermal regimes on the spawning grounds (Hodgson and Quinn 2002; Doctor et al. 2010; Eliason et al. 2011). These differences in when individuals begin their upstream migrations may act as a sorting mechanism as population specific run timing likely increases the probability of an individual finding a member of its group. Third, without stock specific recognition, numerical simulations show that groups can spontaneously 
partition and split accurately based on slight variations in preferred direction, even when they are not able to distinguish among individuals of differing preferences (Couzin et al. 2002, 2005, 2011).

\section{Discussion}

We have presented evidence for a collective navi gation hypothesis for the homeward migration of anadromous salmon and suggest that the role of social interactions in salmon migrations warrants more detailed examination. We observed a negative relationship between straying rate and abundance in seven independent datasets we reviewed, representing three Pacific species and also Atlantic salmon. To complement these data, we also presented a pair of simple theoretical mod els that demonstrate how navigational ability could increase with increasing group size at vari ous stages of homeward migration in salmon. Generally speaking, collective navigation effects are predicted to enhance the ability of the individ ual as well as lead to robust emergent strategies at the group level, not present in any individual. In the following sections, we highlight several out standing questions and limitations of the collective navigation hypothesis presented here and con clude with avenues for future work.

\section{Group size versus abundance}

If salmon complement their individual naviga tional abilities with collective behaviour, the abil ity to home will be influenced by the size of the group in which they travel. Both theory (Niwa 2004; Guttal and Couzin 2010) and observation (Hensor et al. 2005) in non salmonid species sug gest that reduced population density leads to smal ler groups in collectively moving populations rather than fewer groups of the same size. There fore, in years with fewer salmon, individuals may travel in smaller groups, as was observed by (Mathisen 1962). Archived video and sonar recordings maintained by state and federal man agement agencies used to quantify the numbers of returning salmon might provide an opportunity to explore how group size varies across years of known total run sizes. A quantitative relationship between the expected distribution of group sizes in which salmon travel and their population abundance would provide a more mechanistic understanding of the potential role of collective navigation during their migration.

\section{Wild versus hatchery salmon}

Nearly all the salmon comprised in the datasets on straying rates examined were hatchery pro duced, and it is unclear whether hatchery salmon are appropriate proxies for wild fish (Quinn 1993; Keefer and Caudill 2013). Both wild and hatch ery produced Atlantic salmons exhibited a nega tive trend between homing and run size, but the strength of the trend between homing and run size was greater for the hatchery fish (Jonsson et al. 2003). This might indicate that hatchery and escaped aquaculture produced fish exhibit stronger collective effects, possibly because they have been artificially selected for sociality, or this may reflect their prior experience of high densities in the hatchery or farm (Naish et al. 2007). Given the paucity of evidence concerning wild fish stray ing rates, it is unclear whether collective naviga tion operates differently among wild and hatchery fish.

\section{Patterns among species}

One might predict that collective navigation should be most prevalent in more social species (such as sockeye, pink and chum) which have a greater social architecture to support the necessary mechanisms. As discussed above, the increased trend in the more social hatchery fish over the wild fish in Jonsson et al. (2003) lends some sup port to this thinking. An alternative prediction is that collective navigation should be exhibited by populations and species that are more locally adapted and thus under the most intense selection pressures to accurately home (e.g. hypothetically stream type Chinook salmon, sockeye salmon, coho salmon and steelhead). However, if these spe cies spend more time in freshwater, they might have additional opportunity for imprinting and thus might have less need for the collective effect. Also, species that have less opportunity for tempo ral straying as a means of bet hedging, like pink salmons with their fixed 2 year life cycle, might have increased pressure for spatial straying (The dinga et al. 2000; Mortensen et al. 2002; Buoro and Carlson 2014) and therefore less incentive to employ collective navigation. Currently, a lack of robust straying estimates and run sizes among 
species (however, see Westley et al. 2013) impedes the testing of these predictions.

\section{Ecological and evolutionary implications}

A density dependent dispersal rate, in salmon or any migratory species using collective navigation, would have implications for their population dynamics, distribution and patterns of local adap tation. On a local scale, smaller numbers of returning individuals may inhibit their ability to home successfully. Further, copying behaviour, combined with incomplete stock sorting, could lead to net dispersal from small populations to larger ones. Either of these factors might introduce an Allee effect on individual populations, whereby a reduction in population size leads to a reduced rate of returning adults and thus a further decline in the population. While possible, Allee effects in salmon populations are rarely observed (Liermann and Hilborn 1997). At a larger scale, reduced homing at low density should facilitate coloniza tion (Ayson 1921; Emery 1981; Kwain and Law rie 1981; Becker et al. 2007; Correa and Gross 2008), which is profoundly important for salmon because colonization (post glacial, including the present time in Alaska) has been a dominant pro cess in salmon ecology. Across multiple scales, sal monids are locally adapted (Taylor 1991; Fraser et al. 2011; Westley et al. 2012) and there is much interpopulation genetic heterogeneity. The increase in straying rate due to declining popula tions could increase gene flow between local popu lations, thereby altering population genetic patterns. Additionally, increased dispersal tends to favour a generalist strategy, which in turn pro motes further dispersal. This positive evolutionary feedback could shift the selection regime and lead to much more homogeneity at the species level (Kisdi 2002; Nurmi and Parvinen 2011). We pre dict that simulations that link realistic demo graphic models with density dependent dispersal consistent with collective migration will be espe cially informative.

\section{Collective behaviour throughout the salmon life cycle}

We have focused mainly on the potential role of collective navigation during the adult homing phase, although salmon are social and travel in schools throughout their life cycles, suggesting the benefits of collective navigation need not be lim ited to adults during their homeward migration. On their downstream migration, juvenile salmons often migrate through large lakes where the lack of current renders negative rheotaxis useless. This is especially true for schooling sockeye salmon (Groot 1965) that rely on celestial and magnetic cues to migrate through lakes (Quinn 1980; Quinn and Brannon 1982). By travelling in schools, these fish could increase the probability of successfully navigating to sea in a timely manner (Box 1). Indeed, experiments demonstrate that lar ger schools of juvenile chum and sockeye salmon travel in a more orderly manner and at a faster rate than the smaller groups (Hoar 1958a). Also during this freshwater phase, collective gradient tracking might help juveniles find and remain in water temperatures and other conditions beneficial for feeding and growth. Entering the ocean at an appropriate time is critical for successful foraging and survival (e.g. Scheuerell et al. 2009). Synchro nization in downstream movement of juveniles could facilitate effective collective temporal deci sion making (Conradt and Roper 2005) as to the timing of marine entry, possibly even combining independent cues from separate tributaries for more robust decisions. Upon entering the ocean, pooling of genetically coded information about the direction in which to migrate (Putman et al. 2014), or behaviours to follow (Burke et al. 2014), to reach the feeding grounds might reduce individual error in orientation while en route (Box 1). Once on the feeding grounds, collective taxis could improve an individual's ability to track environmental gradients associated with resources and favourable conditions. Finally, as we have dis cussed throughout, collective navigation may play an important role during the remarkable home ward migration of the adult salmon.

Future directions: testing the collective navigation hypothesis

We suggest several avenues to critically test the collective navigation hypothesis. First, as more dataset becomes available, studies of homing and straying rates as functions of abundance at hierar chical spatial scales (i.e. basin, sub basin, reach, habitat unit) would illuminate the spatial scale and phase of the spawning migration where col lective navigation may be most important. Second, salmon moving past obstacles like dams with fish 
ladders could provide an interesting opportunistic experimental test bed. Swift passage times corre lated with high salmon densities would support the collective navigation hypothesis. Third, experi ments where fish are forced to make binary choices between the water flowing in from two separate sources (e.g. y maze designs) could pro vide a conclusive demonstration. One experimental design could be to allow fish to choose between water with and without an odorant to which they had been imprinted, and our prediction is that lar ger groups would choose the correct arm at lower concentrations than individuals and small groups. For this and the fish ladder scenario, analysis of individual trajectories might provide insight into specific behavioural mechanisms, as in (Berdahl et al. 2013). Additionally, we note that the simple comparison of straying rate and abundance could be extended to other taxa that make long distance migrations in groups to discrete locations and are routinely tagged, like birds, to explore the extent of collective navigation in nature.

\section{Summary and closing thoughts}

We have presented a hypothesis that collective navigation during the homeward migration of anadromous salmon improves their capacity to return to natal sites. The evidence suggests that the necessary requirements for collective naviga tion to be operating in migrating salmon are likely met; salmons form schools for the downstream seaward part of their journey, are aggregated at sea, consistent with schooling behaviour, and con tinue to school during the freshwater upstream portion of their homeward journey, potentially even increasing their sociality during this phase. Salmon can detect population specific odours and appear to sort into stock specific groups as they approach the home rivers from sea. Taken as a whole, the evidence is consistent with collective navigation acting as complementary mechanism contributing to the remarkable ability of individual salmon homing to natal locations.

We hope this paper will prompt conversation and research to critically test the collective naviga tion hypothesis presented here and to identify spe cific mechanisms behind the observed patterns. Although focused here on salmon, the collective navigation hypothesis likely applies to other social taxa that make long distance migrations. Across many taxa, research to date has implicitly assumed that map, compass and piloting processes are products of the individual alone (see, for exam ple, reviews by Bingman and Cheng 2005; Papi 2006). Broadening the focus from the individual to the collective might unveil fundamental mecha nisms underpinning the great mystery of animal migrations.

\section{Acknowledgements}

We thank James Anderson, Chloe Bracis, Rich Brenner, Jeff Guyon and Colin Torney for conver sations that inspired and shaped this manuscript and two anonymous referees for critically reading the manuscript and suggesting substantial improvements. Special thanks go to Kate Myers for providing and interpreting the high seas seine net data. Funded by NSF awards PHY 0848755 , EAGER 1251585, and CNH 1211972; U.S. Office of Naval Research award N00014 091 1074; U.S. Army Research Office grant W911NG 111 0385; Leverhulme Early Career Fellowship; H. Mason Keeler Endowment; and the Yukon Foundation.

\section{References}

Arganda, S., Pérez Escudero, A. and de Polavieja, G.G. (2012) A common rule for decision making in animal collectives across species. Proceedings of the National Academy of Sciences 109, 2050820513.

Ayson, L.F. (1921) Quinnat and sockeye salmon in New Zealand waters. Pacific Fisherman 19, 25.

Banks, J.W. (1969) A review of the literature on the upstream migration of adult salmonids. Journal of Fish Biology 1, 85136.

Beauchamp, G. (2011) Long distance migrating species of birds travel in larger groups. Biology Letters 7 , 692694.

Becker, L.A., Pascual, M.A. and Basso, N.G. (2007) Colonization of the Southern Patagonia Ocean by exotic Chinook salmon. Conservation Biology 21, 13471352.

Berdahl, A., Torney, C.J., Ioannou, C.C., Faria, J.J. and Couzin, I.D. (2013) Emergent sensing of complex environments by mobile animal groups. Science $\mathbf{3 3 9}$, 574576 .

Bingman, V.P. and Cheng, K. (2005) Mechanisms of ani mal global navigation: comparative perspectives and enduring challenges. Ethology Ecology \& Evolution 17, 295318.

Biro, D., Sumpter, D.J.T., Meade, J. and Guilford, T. (2006) From compromise to leadership in pigeon hom ing. Current Biology 16, 21232128. 
Bonabeau, E., Dagorn, L. and Fréon, P. (1999a) Scaling in animal group size distributions. Proceedings of the National Academy of Sciences 96, 44724477.

Bonabeau, E., Dorigo, M. and Theraulaz, G. (1999b) Swarm Intelligence: From Natural to Artificial Systems, Vol. 4. Oxford University Press, New York.

Bracis, C. and Anderson, J.J. (2012) An investigation of the geomagnetic imprinting hypothesis for salmon. Fisheries Oceanography 21, 170181.

Brannon, E.L. and Quinn, T.P. (1990) Field test of the pheromone hypothesis for homing by Pacific salmon. Journal of Chemical Ecology 16, 603609.

Buoro, M. and Carlson, S.M. (2014) Life history syn dromes: Integrating dispersal through space and time. Ecology Letters 17, 756767.

Burke, B.J., Anderson, J.J. and Baptists, A.M. (2014) Evi dence for multiple navigational sensory capabilities of Chinook salmon. Aquatic Biology 20, 7790.

Camazine, S. (2003) Self-organization in Biological Systems. Princeton University Press, Princeton.

Codling, E.A., Pitchford, J.W. and Simpson, S.D. (2007) Group navigation and the many wrongs principle in models of animal movement. Ecology 88, 18641870.

Condorcet, N. (1785) Essai sur l'application de l'analyse à la probabilité des décisions rendues à la pluralité des voix. L'Imprimerie Royale, Paris.

Conradt, L. and Roper, T.J. (2005) Consensus decision making in animals. Trends in Ecology $\mathcal{E}$ Evolution 20 , 449456.

Cooke, K., Hungar, R., Groot, C. and Tolson, G. (1987) Data record of adult sockeye salmon and other fish species captured by purse seine in Queen Charlotte Strait, Johnstone Strait and the Strait of Georgia in 1985 and 1986. Canadian Data Report of Fisheries and Aquatic Sciences 680, 1127.

Correa, C. and Gross, M.R. (2008) Chinook salmon invade southern South America. Biological Invasions 10, 615639.

Courtenay, S.C., Quinn, T.P., Dupuis, H.M.C., Groot, C. and Larkin, P.A. (1997) Factors affecting the recogni tion of population specific odours by juvenile coho sal mon. Journal of Fish Biology 50, 10421060.

Couzin, I.D. (2007) Collective minds. Nature 445, 715 715.

Couzin, I.D. (2009) Collective cognition in animal groups. Trends in Cognitive Sciences 13, 3643.

Couzin, I.D. and Franks, N.R. (2003) Self organized lane formation and optimized traffic flow in army ants. Proceedings of the Royal Society of London, B 270, 139146.

Couzin, I.D., Krause, J., James, R., Ruxton, G.D. and Franks, N.R. (2002) Collective memory and spatial sorting in animal groups. Journal of Theoretical Biology 218, 111 .

Couzin, I.D., Krause, J., Franks, N.R. and Levin, S.A. (2005) Effective leadership and decision making in ani mal groups on the move. Nature 433, 513516.
Couzin, I.D., Ioannou, C.C., Demirel, G. et al. (2011) Uninformed individuals promote democratic concensus in animal groups. Science 334, 15781580.

Dann, T.H., Habicht, C., Baker, T.T. and Seeb, J.E. (2013) Exploiting genetic diversity to balance conser vation and harvest of migratory salmon. Canadian Journal of Fisheries and Aquatic Sciences 70, 785793.

Dat, C.G., LeBlond, P.H., Thomson, K.A. and Ingraham, W.J.J. (1995) Computer simulations of homeward migrating Fraser River sockeye salmon: is compass ori entation a sufficient direction finding mechanism in the north east Pacific Ocean? Fisheries Oceanography $\mathbf{4}$, 209216.

Davidson, F.A., Vaughan, E. and Hutchinson, S.J. (1943) Factors influencing the upstream migration of the pink salmon (Oncorhynchus gorbuscha). Ecology 24, 149 168.

Dell'Ariccia, G., Dell'Omo, G., Wolfer, D.P. and Lipp, H. (2008) Flock flying improves pigeons' homing: GPS track analysis of individual flyers versus small groups. Animal Behaviour 76, 11651172.

Detrain, C. and Deneubourg, J. L. (2006) Self organized structures in a superorganism: do ants behave like molecules? Physics of Life Reviews 3, 162187.

Dittman, A. and Quinn, T.P. (1996) Homing in Pacific salmon: mechanisms and ecological basis. Journal of Experimental Biology 199, 8391.

Doctor, K.K., Hilborn, R., Rowse, M. and Quinn, T.P. (2010) Spatial and temporal patterns of upriver migra tion by sockeye salmon populations in the Wood River system, Bristol Bay, Alaska. Transactions of the American Fisheries Society 139, 8091.

Eliason, E.J., Clark, T.D., Hague, M.J. et al. (2011) Differ ences in thermal tolerance among sockeye salmon populations. Science 332, 109112.

Emery, L. (1981) Range extension of pink salmon (Oncorhynchus gorbuscha) into the lower Great Lakes. Fisheries 6, 710 .

Faucher, K., Parmentier, E., Becco, C., Vandewalle, N. and Vandewalle, P. (2010) Fish lateral system is required for accurate control of shoaling behaviour. Animal Behaviour 79, 679687.

Flack, A., Pettit, B., Freeman, R., Guilford, T. and Biro, D. (2012) What are leaders made of? The role of indi vidual experience in determining leader follower rela tions in homing pigeons. Animal Behaviour 83, 703 709.

Folmar, L.C. and Dickhoff, W.W. (1980) The parr smolt transformation (smoltification) and seawater adapta tion in salmonids: a review of selected literature. Aquaculture 21, 137.

Franks, N.R., Pratt, S.C., Mallon, E.B., Britton, N.F. and Sumpter, D.J. (2002) Information flow, opinion polling and collective intelligence in house hunting social insects. Philosophical Transactions of the Royal Society of London, Series B: Biological Sciences 357, 15671583. 
Fraser, D.J., Duchesne, P. and Bernatchez, L. (2005) Migratory charr schools exhibit population and kin associations beyond juvenile stages. Molecular Ecology 14, 31333146 .

Fraser, D.J., Weir, L.K., Bernatchez, L., Hansen, M.M. and Taylor, E.B. (2011) Extent and scale of local adap tation in salmonid fishes: review and meta analysis. Heredity 106, 404420.

Galton, F. (1907) Vox populi. Nature 75, 450451.

Griffiths, S.W. and Ward, A.J.W. (2011) Social recogni tion of conspecifics. In: Fish Cognition and Behaviour, 2nd edn (eds C. Brown, K. Laland and J. Krause). John Wiley and Sons, Hoboken, pp. 186.

Groot, C. (1965) On the orientation of young sockeye sal mon (Oncorhynchus nerka) during their seaward migra tion out of lakes. Behaviour Supplement 14, 1198.

Groot, C. (1972) Migration of yearling sockeye salmon (Oncorhynchus nerka) as determined by time lapse pho tography of sonar observations. Journal of the Fisheries Research Board of Canada 29, 14311444.

Grunbaum, D. (1998) Schooling as a strategy for taxis in a noisy environment. Evolutionary Ecology 12, 503522.

Gueron, S. (1998) The steady state distributions of coag ulation fragmentation processes. Journal of Mathematical Biology 37, 127.

Gueron, S. and Levin, S.A. (1995) The dynamics of group formation. Mathematical Biosciences 128, 243264.

Guttal, V. and Couzin, I.D. (2010) Social interactions, information use, and the evolution of collective migra tion. Proceedings of the National Academy of Sciences 107, 1617216177.

Handegard, N.O., Leblanc, S., Boswell, K., Tjostheim, D. and Couzin, I.D. (2012) The dynamics of coordinated group hunting and collective information transfer among schooling prey. Current Biology 22, 12131217.

Hard, J. and Heard, W. (1999) Analysis of straying vari ation in Alaskan hatchery chinook salmon (Oncorhynchus tshawytscha) following transplantation. Canadian Journal of Fisheries and Aquatic Sciences 56, 578589.

Hartt, A. (1975) Problems in sampling Pacific salmon at sea. International North Pacific Fisheries Commission Bulletin 32, 165214.

Hasler, A.D. (1966) Underwater Guideposts in Homing of Salmon. University of Wisconsin Press, Madison.

Hasler, A.D. and Scholz, A.T. (1983) Olfactory Imprinting and Homing in Salmon: Investigations into the Mechanism of the Imprinting Process. Springer Verlag, Berlin.

Hendry, A.P., Castric, V., Kinnison, M.T. and Quinn, T.P. (2004) The evolution of philopatry and dispersal: hom ing versus straying in salmonids. In: Evolution Illuminated: Salmon and Their Relatives. (eds A.P. Hendry and S.C. Stearns). Oxford University Press, New York, pp. 5391.

Hensor, E., Couzin, I.D., James, R. and Krause, J. (2005) Modelling density dependent fish shoal distributions in the laboratory and field. Oikos 110, 344352.
Herskin, J. and Steffensen, J.F. (1998) Energy savings in sea bass swimming in a school: measurements of tail beat frequency and oxygen consumption at different swimming speeds. Journal of Fish Biology 53, 366 376.

Hoar, W.S. (1951) The behaviour of chum, pink and coho salmon in relation to their seaward migration. Journal of the Fisheries Research Board of Canada 8, 241263.

Hoar, W.S. (1958a) Rapid learning of a constant course by travelling schools of juvenile pacific salmon. Journal of the Fisheries Research Board of Canada 15, 251274.

Hoar, W.S. (1958b) The evolution of migratory behav iour among juvenile salmon of the genus Oncorhynchus. Journal of the Fisheries Research Board of Canada 15, 391428.

Hoar, W.S. (1976) Smolt transformation: evolution, behaviour, and physiology. Journal of the Fisheries Board of Canada 33, 12331252.

Hodgson, S. and Quinn, T.P. (2002) The timing of adult sockeye salmon migration into fresh water: adapta tions by populations to prevailing thermal regimes. Canadian Journal of Zoology 80, 542555.

Hughes, N.F. (2004) The wave drag hypothesis: an explanation for size based lateral segregation during the upstream migration in salmonids. Canadian Journal of Fisheries and Aquatic Sciences 61, 103109.

Hutchison, M.J. and Iwata, M. (1997) A comparative analysis of aggression in migratory and non migratory salmonids. Environmental Biology of Fishes 50, 209 215.

Johnsen, P.B. (1982) A behavioral control model for homestream selection in migratory salmonids. In: Proceedings of the Salmon and Trout Migratory Behavior Symposium. (eds E.L. Brannon and E.O. Salo). Seattle, WA, School of Fisheries, University of Washington, pp. 266273.

Johnson, W.E. and Groot, C. (1963) Observations on the migration of young sockeye salmon (Oncorhynchus nerka) through a large, complex lake system. Journal of the Fisheries Research Board of Canada 20, 919938.

Jonsson, B. and Jonsson, N. (2011) Ecology of Atlantic Salmon and Brown Trout. Habitat as a template for life histories. In: Fish \& Fisheries Series 33. Springer, Dordrecht.

Jonsson, B., Jonsson, N. and Hansen, L. (2003) Atlantic salmon straying from the River Imsa. Journal of Fish Biology 62, 641657.

Kao, A.B. and Couzin, I.D. (2014) Decision accuracy is complex environments is often maximized by small group sizes. Proceedings of the Royal Society B: Biological Sciences 281, 20133305.

Keefer, M.L. and Caudill, C.C. (2013) Homing and stray ing by anadromous salmonids: a review of mechan isms and rates. Reviews in Fish Biology and Fisheries 24, 136 . 
Keefer, M.L., Peery, C.A. and High, B. (2009) Behavioral thermoregulation and associated mortality trade offs in migrating adult steelhead (Oncorhynchus mykiss): vari ability among sympatric populations. Canadian Journal of Fisheries and Aquatic Sciences 66, 17341747.

King, A.J. and Cowlishaw, G. (2007) When to use social information: the advantage of large group size in indi vidual decision making. Biology Letters 3, 137139.

Kisdi, E. (2002) Dispersal: risk spreading versus local adaptation. The American Naturalist 159, 579596.

Krause, J. and Ruxton, G.D. (2002) Living in Groups. Oxford University Press, New York.

Kwain, W. H. and Lawrie, A.H. (1981) Pink salmon in the Great Lakes. Fisheries 6, 26.

Labelle, M. (1992) Straying patterns of coho salmon (Oncorhynchus kisutch) stocks from southeast Vancouver Island, British Columbia. Canadian Journal of Fisheries and Aquatic Sciences 49, 18431855.

Ladha, K.K. (1992) The Condorcet jury theorem, free speech, and correlated votes. American Journal of Political Science 36, 617634.

Larkin, P.A. and Walton, A. (1969) Fish school size and migration. Journal of the Fisheries Research Board of Canada 26, 13721374.

Leggett, W.C. (1977) The ecology of fish migrations. Annual Review of Ecology and Systematics 8, 285308.

Lenwood, W. Jr., Burton, D.T., Margrey, S.L. and Graves, W.C. (1982) A comparison of the avoidance responses of individual and schooling juvenile Atlantic menha den, Brevoortia tyrannus subjected to simultaneous chlorine and $\delta \mathrm{t}$ conditions. Journal of Toxicology and Environmental Health 10, 10171026.

Liermann, M. and Hilborn, R. (1997) Depensation in fish stocks: a hierarchic Bayesian meta analysis. Canadian Journal of Fisheries and Aquatic Sciences 54, 9761984.

Lorz, H.W. and Northcote, T.G. (1965) Factors affecting stream location, and timing and intensity of entry by spawning kokanee (Oncorhynchus nerka) into an inlet of Nicola Lake, British Columbia. Journal of the Fisheries Board of Canada 22, 665687.

Ma, Q., Johansson, A. and Sumpter, D. (2011) A first principles derivation of animal group size distributions. Journal of Theoretical Biology 283, 3543.

Makris, N.C., Ratilal, P., Symonds, D.T. et al. (2006) Fish population and behaviour revealed by instantaneous continental shelf scale imaging. Science 311, 660663.

Marras, S., Batty, R.S. and Domenici, P. (2012) Informa tion transfer and antipredator maneuvers in schooling herring. Adaptive Behaviour 20, 4456.

Mathisen, O.A. (1962) Photographic enumeration of red salmon escapement. In: Studies of Alaska Red Salmon (ed. T.S. Koo). University of Washington Press, Seattle, pp. 353372 .

McElroy, B., DeLonay, A. and Jacobson, R.B. (2012) Optimum swimming pathways of fish spawning migra tions in rivers. Ecology 93, 2934.
McNicol, R.E., Scherer, E. and Gee, J.H. (1996) Shoaling enhances cadmium avoidance by lake whitefish, Coregonus clupeaformis. Environmental Biology of Fishes 47, 311319.

Milner Gulland, E., Fryxell, J.M. and Sinclair, A.R.E. (2011) Animal Migration: A Synthesis. Oxford Univer sity Press, Oxford, UK.

Mishima, S., Ueno, M. and Kawashima, R. (1965) On the spatial distribution of salmon by means of the analysis from the catch of fish per unit net. Bulletin of the Japanese Society of Scientific Fisheries $\mathbf{3 1}$, 269276.

Mortensen, D.G., Wertheimer, A.C., Maselko, J.M. and Taylor, S.G. (2002) Survival and straying of Auke Creek, Alaska, pink salmon marked with coded wire tags and thermally induced otolith marks. Transactions of the American Fisheries Society 131, 1426.

Mueller, T., O'Hara, R.B., Converse, S.J., Urbanek, R.P. and Fagan, W.F. (2013) Social learning of migratory performance. Science 341, 9991002.

Naish, K.A., Taylor, J.E. III, Levin, P.S. et al. (2007) An evaluation of the effects of conservation and fishery enhancement hatcheries on wild populations of sal mon. Advances in Marine Biology 53, 61194.

Neave, F. (1964) Ocean migrations of Pacific salmon. Journal of the Fisheries Research Board of Canada 21, 12271244.

Nero, R.W. and Huster, M.E. (1996) Low frequency acoustic imaging of Pacific salmon on the high seas. Canadian Journal of Fisheries and Aquatic Sciences $\mathbf{5 3}$, 25131523.

Niwa, H. S. (2004) Space irrelevant scaling law for fish school sizes. Journal of Theoretical Biology 228, 347 357.

Nordeng, H. (1971) Is the local orientation of anadro mous fishes determined by pheromones? Nature 233 , 411413.

Nordeng, H. (1977) A pheromone hypothesis for home ward migration in anadromous salmonids. Oikos $\mathbf{2 8}$, 155159.

NRC National Research Council (1996) Upstream: Salmon and Society in the Pacific Northwest. National Academy Press, Washington, DC.

Nurmi, T. and Parvinen, K. (2011) Joint evolution of specialization and dispersal in structured metapopula tions. Journal of Theoretical Biology 275, 7892.

Olsén, K.H., Petersson, E., Ragnarsson, B., Lundqvist, H. and Jarvi, T. (2004) Downstream migration in Atlantic salmon (Salmo salar) smolt sibling groups. Canadian Journal of Fisheries and Aquatic Sciences 61, 328331.

Papi, F. (2006) Navigation of marine, freshwater and coastal animals: concepts and current problems. Marine and Freshwater Behaviour and Physiology 39, 312.

Partridge, B.L. and Pitcher, T.J. (1980) The sensory basis of fish schools: relative roles of lateral line and vision. Journal of Comparative Physiology 135, 315325. 
Pascual, M.A. and Quinn, T.P. (1991) Evaluation of alternative models of the coastal migration of adult Fraser River sockeye salmon (Oncorhynchus nerka). Canadian Journal of Fisheries and Aquatic Sciences $\mathbf{4 8}$, 799810.

Pitcher, T.J. and Parrish, J.K. (1993) Functions of shoal ing behaviour in teleosts. In: Behaviour of Teleost Fishes, Vol. 2 (ed. T.J. Pitcher). Chapman \& Hall, Lon don, pp. 369439.

Portugal, S.J., Hubel, T.Y., Fritz, J. et al. (2014) Upwash exploitation and downwash avoidance by flap phasing in ibis formation flight. Nature 505, 399402.

Putman, N.F., Lohmann, K.J., Putman, E.M., Quinn, T.P., Klimley, A.P. and Noakes, D.L. (2013) Evidence for geomagnetic imprinting as a homing mechanism in Pacific salmon. Current Biology 23, 312316.

Putman, N.F., Scanlan, M.M., Billman, E.J. et al. (2014) An inherited magnetic map guides ocean navigation in juvenile Pacific salmon. Current Biology 24, 446450.

Quinn, T.P. (1980) Evidence for celestial and magnetic compass orientation in lake migrating sockeye salmon fry. Journal of Comparative Physiology 137, 243248.

Quinn, T.P. (1984) Homing and straying in Pacific sal mon. In: Mechanisms of Migration in Fishes (eds J.D. McCleave, G.P. Arnold, J.J. Dodson and W.H. Neill). Plenum Press, New York, pp. 357362.

Quinn, T.P. (1993) A review of homing and straying of wild and hatchery produced salmon. Fisheries Research 18, 2944

Quinn, T.P. (2005) The Behavior and Ecology of Pacific Salmon and Trout. University of Washington Press, Seattle.

Quinn, T.P. and Brannon, E.L. (1982) The use of celes tial and magnetic cues by orienting sockeye salmon smolts. Journal of Comparative Physiology 147, 547 552.

Quinn, T.P. and Busack, C.A. (1985) Chemosensory rec ognition of siblings in juvenile coho salmon (Oncorhynchus kisutch). Animal Behaviour 33, 5156.

Quinn, T.P. and Fresh, K. (1984) Homing and straying in chinook salmon (Oncorhynchus tshawytscha) from Cowlitz River hatchery, Washington. Canadian Journal of Fisheries and Aquatic Sciences 41, 10781082.

Quinn, T.P. and Hara, T.J. (1986) Sibling recognition and olfactory sensitivity in juvenile coho salmon (Oncorhynchus kisutch). Canadian Journal of Zoology 64, 921925.

Ross, R.M., Backman, T.W.H. and Limburg, K.E. (1992) Group size mediated metabolic rate reduction in Amer ican shad. Transactions of the American Fisheries Society 121, 385390 .

Scheuerell, M.D., Zabel, R.W. and Sandford, B.P. (2009) Relating juvenile migration timing and survival to adulthood in two species of threatened Pacific salmon (Oncorhynchus spp.). Journal of Applied Ecology 46, 983990.
Scholz, A.T., Horrall, R.M., Cooper, J.C. and Hasler, A.D. (1976) Imprinting to chemical cues: the basis for homestream selection in salmon. Science 192, 1247 1249.

Schroeder, R.K., Lindsay, R.B. and Kenaston, K.R. (2001) Origin and straying of hatchery winter steel head in Oregon coastal rivers. Transactions of the American Fisheries Society 130, 431441.

Seeley, T.D. and Buhrman, S.C. (1999) Group decision making in swarms of honey bees. Behavioral Ecology and Sociobiology 45, 1931.

Shaw, A.K. and Couzin, I.D. (2013) Migration or resi dency? the evolution of movement behaviour and information usage in seasonal environments. The American Naturalist 181, 114124.

Sholes, W. and Hallock, R. (1979) An evaluation of rear ing fall run chinook salmon, Oncorhynchus tshawytscha, to yearlings at feather river hatchery, with a comparison of returns from hatchery and downstream releases. California Department of Fish and Game 65, 239255.

Simms, S.E. and Larkin, P.A. (1977) Simulation of dis persal of sockeye salmon (Oncorhynchus nerka) under yearlings in Babine Lake. Journal of the Fisheries Research Board of Canada 34, 13791388.

Simons, A.M. (2004) Many wrongs: the advantage of group navigation. Trends in Ecology \& Evolution 19, 453455.

Strandburg Peshkin, A., Twomey, C.R., Bode, N.W.F., et al. (2013) Visual sensory networks and effective information transfer in animal groups. Current Biology 23, R709 R711.

Sumpter, D.J. (2006) The principles of collective animal behaviour. Philosophical Transactions of the Royal Society B: Biological Sciences 361, 522.

Sumpter, D.J., Krause, J., James, R., Couzin, I.D. and Ward, A.J. (2008) Consensus decision making by fish. Current Biology 18, 17731777.

Surowiecki, J. (2004) The wisdom of the crowds: why the many are smarter than the few. Little Brown, London.

Taylor, E.B. (1991) A review of local adaptation in Sal monidae, with particular reference to Pacific and Atlantic salmon. Aquaculture 98, 185207.

Thedinga, J.F., Wertheimer, A.C., Heintz, A.R., Maselko, J.M. and Rice, S.D. (2000) Effects of stock, coded wire tagging, and transplant on straying of pink salmon (Oncorhynchus gorbuscha) in southeastern Alaska. Canadian Journal of Fisheries and Aquatic Sciences 57, 2076 2085.

Torney, C.J., Neufeld, Z. and Couzin, I.D. (2009) Context dependent interaction leads to emergent search behav iour in social aggregates. Proceedings of the National Academy of Sciences 106, 2205522060.

Torney, C.J., Levin, S.A. and Couzin, I.D. (2010) Special ization and evolutionary branching within migratory 
populations. Proceedings of the National Academy of Sciences 107, 2039420399.

Torney, C.J., Berdahl, A. and Couzin, I.D. (2011) Signal ling and the evolution of cooperative foraging in dynamic environments. PLoS Computational Biology $\mathbf{7}$, e1002194.

Ueda, H. (2012) Physiological mechanisms of imprinting and homing migration in Pacific salmon Oncorhynchus spp. Journal of Fish Biology 81, 543558.

Unwin, M.J. and Quinn, T.P. (1993) Homing and stray ing patterns of chinook salmon (Oncorhynchus tshawytscha) from a New Zealand hatchery: spatial distribution of strays and effects of release date. Canadian Journal of Fisheries and Aquatic Sciences 50, 1168 1175.

Ward, A.J., Webster, M.M. and Hart, P.J.B. (2007) Social recognition in wild fish populations. Proceedings of the Royal Society B: Biological Sciences 274, 10711077.

Ward, A.J., Sumpter, D.J., Couzin, I.D., Hart, P.J. and Krause, J. (2008) Quorum decision making facilitates information transfer in fish shoals. Proceedings of the National Academy of Sciences 105, 69486953.

Ward, A.J., Herbert Read, J.E., Sumpter, D.J. and Krause, J. (2011) Fast and accurate decisions through collec tive vigilance in fish shoals. Proceedings of the National Academy of Sciences 108, 23122315.

Westley, P.A.H., Ward, E.J. and Fleming, I.A. (2012) Fine scale local adaptation in an invasive freshwater fish has evolved in contemporary time. Proceedings of the Royal Society B: Biological Sciences 280, 1751.

Westley, P.A.H., Quinn, T.P. and Dittman, A.H. (2013) Rates of straying by hatchery produced Pacific salmon (Oncorhynchus spp.) and steelhead (Oncorhynchus mykiss) differ among species, life history types, and populations. Canadian Journal of Fisheries and Aquatic Sciences 70, 735746.

Winberg, S. and Olsén, H. (1992) The influence of rear ing conditions on the sibling odour preference of juve nile arctic charr, Salvelinus alpinus L. Animal Behaviour 44, 157164. 